\title{
Indoor school environment: easy and low cost to assess inorganic pollutants
}

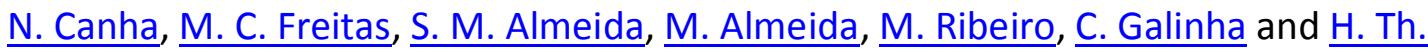
Wolterbeek

Link Out to this Article at Instituto Politécnico de Lisboa:

- Servicos $9^{\circ}$ Texto Integral @ b-on

- Download PDF (304.5 KB)

- View HTML

- Permissions \& Reprints

- Related

- Issue

- Journal

\begin{abstract}
Total particulate matter (TPM) was passively collected inside two classrooms of each of five elementary schools in Lisbon, Portugal. TPM was collected in polycarbonate filters with a $47 \mathrm{~mm}$ diameter, placed inside of uncovered plastic petri dishes. The sampling period was from 19 May to 22 June 2009 (35 days exposure) and the collected TPM masses varied between $0.2 \mathrm{mg}$ and $0.8 \mathrm{mg}$. The major elements were $\mathrm{Ca}, \mathrm{Fe}, \mathrm{Na}, \mathrm{K}$, and $\mathrm{Zn}$ at $\mu \mathrm{g}$ level, while others were at ng level. Pearson's correlation coefficients above 0.75 (a high degree of correlation) were found between several elements. Soil-related, traffic soil re-suspension and anthropogenic emission sources could be identified. Blackboard chalk was also identified through Ca large presence. Some of the determined chemical elements are potential carcinogenic. Quality control of the results showed good agreement as confirmed by the application of $u$-score test.
\end{abstract}

\section{Keywords}

Total particulate matter - Classrooms - Children - Chemical elements 